\title{
ENSAYO/ESSAY
}

\section{JOSÉ MARTÍ, PRECURSOR DEL 98, MÁXIMO EXPONENTE DEL PERIODISMO DEL SIGLO XIX}

Enrique Ríos Vicente ${ }^{\mathbf{1}}$ : Universidad Complutense de Madrid. España. enrios@eucmax.sim.ucm.es

\section{RESUMEN}

José Martí fue el periodista mejor informado del siglo XIX, además del más completo porque tocaba todos los géneros periodísticos. Una gran parte de la obra de este escritor cubano queda esparcida en multitud de periódicos y revistas. En este artículo se lleva a cabo un recorrido por sus diferentes etapas como periodista. En sus primeros pasos Martí se da cuenta de que la palabra era el mejor medio para desarrollar su vocación y publica sus primeros versos en 1868 en un periódico local. En su etapa inicial desarrolla un periodismo puramente político. A continuación, en México, inicia una etapa de periodismo total. En Estados Unidos desarrollará su labor periodística más intensa a escala continental, publicando en 1880 su primer artículo en inglés en la revista The Hour. En la última etapa, el periodismo de Martí llega a su cumbre con el periódico del Partido Revolucionario Cubano, Patria, que será su obra maestra.

PALABRAS ClAVE: José Martí - Periodista - Etapas - Periodismo Político - Escala continental.

\footnotetext{
1 Autor correspondiente:

Enrique Ríos Vicente: Titular de Periodismo de la Facultad de Ciencias de la Información de la Universidad Complutense de Madrid. España.

Correo: enrios@eucmax.sim.ucm.es
} 


\title{
JOSE MARTI, PRECURSOR OF 98, MAXIMUM EXPONENT OF XIX CENTURY JOURNALISM
}

\begin{abstract}
Jose Marti was the best informed journalist of the nineteenth century, in addition to the more complete because he played all journalistic genres. Much of the work of this Cuban writer is scattered in many newspapers and magazines. This article conducts a tour of the various stages as a journalist. In its infancy Marti realizes that the word was the best way to develop their vocation and published his first poems in 1868 in a local newspaper. In its initial stage develops a purely political journalism. Here in Mexico, began a period of Total journalism. In the United States shall work more intense journalistic continental scale, publishing in 1880 his first article in English in the journal The Hour. In the last stage, Marti journalism reached its summit with the Cuban Revolutionary Party newspaper, Patria, to be his masterpiece.
\end{abstract}

KEYWORDS: Jose Marti - Journalist - Stages - Political Journalism - Continental Scale.

\section{INTRODUCCIÓN}

\section{De todos los oficios prefiero el de la imprenta, porque es el que más ha ayudado a la dignidad del hombre. (Martí)}

Si Martí habla de esta forma de la imprenta es porque la conoce y practica como tipógrafo en su fecunda vida periodística. Fue el periodista mejor informado del siglo XIX (Gastón Baquero, 1995: Casa América), pero habría que añadir que era el periodista más formado y completo, pues tocaba todos los géneros periodísticos y nos ha dejado una obra de algún modo inagotable.

Y continúa siendo todavía la mina a medio volcar, el metal que está a la vez a flor de tierra y metido en vericuetos oscuros del espíritu y del idioma y que es preciso badear muchos años más para sacarlo afuera hasta la última limadura de oro (Mistral, 1938). Nunca la lengua nuestra tuvo mejores tintas, caprichos y bizarrías (Darío, 1929:236).

Aunque la poetisa chilena se refiere a toda la obra de Martí, sin duda que en su pensamiento estaba presente ante todo la obra literaria; sin embargo, no debe pasarse por alto que el escritor cubano una buena parte de su obra la deja esparcida en multitud de periódicos y revistas.

Por ello se ha dicho que es uno de los más sobresalientes casos del escritor trasvasado casi íntegramente en el periodismo. Sus primeras manifestaciones escritas -debo añadir que también las últimas- están destinadas a la hoja periódica, y después, a todo lo largo de su vida, llenará miles de páginas para los diarios, unas veces obligado por el imperio de la necesidad, otras por el de sus ideas y fines políticos. 
Salvo sus discursos, sus producciones teatrales y sus versos, todo lo demás... puede decirse que surgió en el molde periodístico (Lizaso, 1943).

¿Siente Martí de joven la llamada del periodismo? ¿0 más bien, el mismo acude al periodismo como el mejor medio de comunicación colectiva? Cuando despertó a la vida intelectual, en la casa de su maestro Mendive, vio en el periódico el vehículo para combatir la tiranía (Lizaso, 1943:11), incluso su iniciación a las ideas krausistas (Oria, 1987: 159).

Creo que se puede asegurar, y se puede probar siguiendo las etapas de su vida periodística, que desde adolescente apela al periodismo, pues no en vano, según sus palabras, tiene la prensa periódica altísimas misiones: es la una explicar en la paz, y en la lucha, fortalecer y aconsejar (Martí, 1955:189).

En 1862, cuando apenas sobrepasaba los nueve años, -habla nacido el 28 de enero de 1853-, cuando ayudaba a su padre que era Capitán Juez en Hanábana (Jagüey Grande), el niño José Julián Martí Pérez conoce de cerca los horrores de la esclavitud y jura ante el cadáver de un esclavo ahorcado, lavar con su vida el crimen: Rojo como el desierto / salió el sol al horizonte / y alumbró a un esclavo muerto, / colgado a un seibo del monte //Un niño lo vio: tembló / de pasión por los que gimen: / Y, al pie del muerto, juró / lavar con su vida el crimen! (Martí, 1955: 189).

No es que naciera en ese momento su vocación periodística, pero si el terror hiere su fina sensibilidad de tal forma que se entregaría totalmente a la redención de "los que gimen" y a la lucha liberadora de su patria oprimida y de las patrias americanas que pudieran serlo en la andadura del tiempo. De 1863 a 1865 estudia en el Colegio de San Anacleto, ayudado, económicamente, por su padrino Arazoza. Con sus padres y sus cinco hermanas vivía en la estrechez. También aquellas impresiones de la carencia y tristeza del hogar quedarían reflejadas más tarde en uno de los poemas de sus Versos Libres: Era yo niño / y con filial afán miraba el cielo...! Cuán pobre a mi avaricia parecía / el amor de mi hogar! (Martí, 1995) Por todas estas carencias, no es raro que su fina sensibilidad y sus dotes precoces encontraran el apoyo y la comprensión no sólo de su padrino Francisco Arazoza, sino también la del profesor Rafael María de Mendive, "verdadero padre espiritual de Martí" (Espina, 1970:39) que seria, su maestro, su amigo; y su primer incitador hacia la vocación del periodismo.

En la década de los 60 a los 70, los partidarios del separatismo eran muchos en la Isla y no pocos en España. Entre ellos se contaba Mendive, importante en el circulo intelectual de La Habana, que reunía en su casa a un buen grupo de partidarios de Cuba libre, convirtiendo su hogar en un foco de separatismo parecido al de los precursores y próceres de la emancipación del resto de las naciones iberoamericanas que se desuncieron del yugo español durante el primer período constitucional de la Península. ¿Qué se hacía en la casa de Mendive? Allí, comenta Espina, en tertulia de amigos, se hablaba, se discutía, se dibujaban actitudes y se leían con fervor patriótico textos y propagandas revolucionarias. Pocos en número los tertulianos, a nadie cedían en fervor rebelde. Y uno de los más entusiastas era José Martí...(Espina, 1970:40). 
Este párrafo de Antonio Espina le revela gran conocedor del alma de Martí y de los próceres de los países americanos, En cuanto a Martí, refleja la llamada de la propaganda y de la prensa, pues en casa de Mendive se "leían con fervor patriótico textos y propagandas revolucionarias". La vocación redentora, Martí ya la tenía desde mucho antes; incluso era dueño de la palabra, tanto oral como escrita, pues desde pequeño devora libros y asimila cultura: De día va a la pequeña escuela de barrio. Como dice Gonzalo de Quesada, ansia la calma multicolor del sol para entregarse de noche, ya solo en su cuarto, a la lectura o a la rima.

Vive así los episodios emocionantes de "Los tres mosqueteros", de Alejandro Dumas considerada por él más que novela, poema-; lee una vieja edición del Quijote; saborea los sonetos de Fray Luis de León. Y si lee a hurtadillas, con mayor sigilo tiene que rimar y mantener ocultos sus primeros versos juveniles.

\section{ANÁLISIS}

\subsection{Primeros pasos periodísticos.}

Sin duda, Martí, poseedor de la palabra, conoce la prensa en casa de Mendive y se da cuenta de que era el mejor medio para desarrollar la vocación á la que era llamado. En 1868 publica sus primeros versos en un periódico local, El Álbum, de la Villa de Guanabacoa; en este caso, dedicados a la segunda esposa de Mendive. Comienza la conquista de la prensa con unos versos, pero al año siguiente, cursando segundo de Bachillerato, insiste en El Diablo Cojuelo, (La Habana, 19 de enero de 1869), que aunque publicado por su "hermano del alma", Fermín Valdés Domínguez (Quesada, 1947:19), lo redacta él solo casi por completo.

En el publica su primer editorial y primer escrito patriótico, en el que ridiculiza al gobierno despótico de la Isla. Utiliza el periódico como arma política sobre todo a raíz de la libertad temporal de prensa decretada en enero de 1869 por el Capitán General Domingo Dulce. De aquellos momentos son sus palabras: Nunca supe, se puede leer en El Diablo Cojuelo, lo que era público ni lo que era escribir para él, mas, a fe de diablo honrado, aseguro que ahora como antes nunca tuve tampoco miedo de hacerlo.

El 21 del mismo mes publica el soneto "110 de Octubre!" en el periódico manuscrito El Siboney con motivo del alzamiento de Carlos Manuel de Céspedes. Dos de sus estrofas reflejan su entusiasmo: De su fuerza y heroica valentía / tumbas los campos son, y su grandeza / dragada y mancha horrible cobardía /. Gracias a Dios que !al fin con entereza / rompe Cuba el dogal que la oprimía / y altiva y libre yergue su cabeza!

En El Diablo Cojuelo, debido a su carácter satírico, utiliza Martí el comentario humorístico para denunciar los males de la colonia, pero este fenómeno es sólo atribuíble a su naturaleza juvenil (García Cueto, 1977:71) porque, salvo muy contadas excepciones, que se refieren a trabajos de otra índole, el tema político, el de la defensa de la patria o el de la lucha por la independencia, estarán siempre tratados con el tono serio, si se quiere grave, que exige la titánica empresa en la que se halla envuelto. 
Poco más tarde publica otros escritos patrióticos en La Patria Libre (La Habana, 22 de enero, 1869), periódico que dirige y en el que colaboran amigos y compañeros suyos, así como su maestro Rafael Ma de Mendive. En él publica el poema dramático "Abdala", lleno de alusiones simbólicas que representa a la patria irredenta. Martí parece identificarse con el personaje central quien dice: ioh qué dulce es morir cuando se muere luchando audaz por defender la patria!

Sin duda, por este tipo de manifestaciones y por su asidua asistencia a la casa de Mendive, el joven Martí era considerado por las autoridades españolas como un ardiente revolucionario. Su maestro Mendive había sido detenido y desterrado con motivo de los sucesos subversivos del Teatro Villanueva de La Habana.

Primero fue el maestro y poco después el discípulo. Martí da motivo para ello a raíz de una carta que escribieron él y su amigo Valdés Domínguez a un condiscípulo suyo que se había alistado en las tropas españolas y a quien tachan de traidor. Un registro de la policía en la casa de Valdés Domínguez conduce al descubrimiento de la carta y a la detención y procesamiento de ambos. Como Martí se declara totalmente responsable (Quesada, es condenado a seis años de prisión. Su amigo Valdés Domínguez, a seis meses.

\subsection{Etapa inicial: Periodismo político (1871-1875).}

"Dante no estuvo en presidio. Si hubiera sentido desplomarse sobre su cerebro las bóvedas oscuras de aquel tormento de la vida, hubiera desistido de pintar su Infierno. Las hubiera copiado, y lo hubiera pintado mejor", escribe Martí en El Presidio Político en Cuba, y esa es la mejor alusión a los espantosos horrores de Las Canteras de San Lázaro a las que fue condenado. El quebranto de su salud fue tan considerable que se teme por su vida y debido a las peticiones y ruegos de sus padres, y sobre todo a la intervención del dueño de las canteras donde realizaban trabajos forzados los presos, José María Sardá Gironella, Martí fue trasladado a la residencia del catalán en la Isla de Pinos, donde se repone desde octubre a enero. Debido a esas intervenciones se le conmuta la pena por la deportación a España.

El 15 de enero de 1871 embarca para España en el vapor "Guipúzcoa" y arriba a Cádiz a finales del mismo mes. Hacia mediados de febrero Martí se encuentra ya en Madrid. Desde que Martí desembarcara en Cádiz comienza su labor periodística, puesto que ya tenía en la mente lo que diría más tarde de la prensa: tiene la prensa periódica altísimas misiones: es la una explicar en la paz, y en la lucha, fortalecer y aconsejar.

Martí va a tratar de explicar a los españoles la situación cubana. Nada más llegar a Madrid publica el alegato El presidio político en Cuba, del que ya publicara anteriormente un avance en un periódico de Sevilla, "La Cuestión Cubana". Como los deportados gozaban en la Península de plena libertad de acción, de residencia y de trabajo, Martí, dice Espina, se adapta pronto a la vida madrileña; frecuenta el Ateneo, los cafés, los teatros, algunos salones de prosapia y los medios obreros, donde puede darse cuenta de las míseras condiciones en que se desenvuelve la vida del pueblo... 
El ambiente de la situación era idóneo y atravesaba un buen momento para explicar a todos los españoles no sólo el "estado de las cárceles" sino todo el complejo mundo de la cuestión cubana que interesaba a todos, declarándose unos en favor y otros en contra, pero que apasionaba a la mayoría. Amante y conocedor de la prensa, y sin duda ansiada como el mejor instrumento de comunicación, Martí logra colaboraciones en periódicos como La Discusión y El Jurado Federal, de Madrid; La Soberanía Nacional de Cádiz y La Cuestión Cubana, de Sevilla, entre otros.

Matriculado en Derecho en la Universidad Complutense, Martí comienza una etapa importante de su vida, ya que es el período en que cimienta su formación, Derecho y Filosofía y Letras (Madrid y Zaragoza), y amplia su cultura en distintos campos, algunos de los cuales apenas aún han sido estudiados, como el de su periodismo científico, recientemente descubierto y estudiado por el periodista cubano, Alexis Schlauter, en la revista Bohemia, "El último libro que regaló Martí" y "Lo alemán en la cultura universal de José Martí" pero sobre todo en su libro sobre este tema, posiblemente ya editado en Cuba.

La actividad de Martí en Madrid y Zaragoza es febril. En Madrid muchas noches acude, dice Espina, a una tertulia del café de las Columnas, de la Puerta del Sol, donde se reúne con sus compatriotas Calixto García, José Ramón Betancourt, Francisco Ramos, Rafael María de Labra y los españoles Eduardo Benot, Suárez Bravo y Moreno Godínez, entre otros (Espina, 1970:52).

Además se relaciona con el mundo de la literatura, del teatro, del arte y de la ciencia. Sin duda, la mayor parte de estas raíces de la cultura martiana y sus contactos no han sido suficientemente investigados; de ahí que sobre esta etapa tan importante de Martí en España aún permanece casi en la sombra y por ello los autores sitúan su primera etapa periodística a su llegada a México en 1875 . Pero no se entiende que Martí siendo un niño acuda a un periódico manuscrito escolar para expresar sus ideas en favor de la libertad de Cuba y no lo haga en su período de estudiante en Madrid. Sin duda, su periodismo político comienza en España y se impone investigar las hemerotecas, archivos, etc. de las ciudades donde vive, incluso las de aquellas ciudades que visita, bastantes, sin duda.

La vida española se ve agitada con la abdicación de Amadeo de Saboya el 11 de febrero de 1873 y la proclamación de la República. Tanto Martí como su amigo Valdés Domínguez asisten al acto de proclamación en el Congreso. Dos días más tarde aparece un opúsculo de Martí La República española ante la Revolución cubana: "Hambre de buena voluntad, saludo a la República que triunfa; la saludo hoy como la maldeciré mañana, criando una República ahogue a otra República. Si Cuba proclama su independencia por el mismo hecho que se proclama la República, ¿cómo ha de negar la República española a Cuba su derecho a ser libre, que es el mismo que ella usó para serlo?" (Martí, 1873).

Parece que el alegato de Martí cae en el vacío debido al apasionamiento por el estreno del nuevo régimen. Algunas otras voces, tanto en La Habana como en Madrid, se unen a los mensajes políticos del opúsculo de Martí, quien además, vuelve a insistir 
con dos artículos "La Solución" y "Las Reformas" que aparecen en un periódico de Sevilla. El joven cubano sabe perfectamente que algunos ilustres políticos españoles, como el segundo presidente, $\mathrm{Pi}$ y Margall, son proclives a solucionar cuanto antes el problema cubano, como lo habían expuesto no pocos en la prensa y el mismo Pi y Margall en la prensa y en el Parlamento.

Pero también sabe Martí que estos "filibusteros de honor" como se llaman a sí mismos algunos intelectuales madrileños amigos de los cubanos, están expuestos a la hostilidad general y al rechazo. Vencían los partidarios de los negocios fáciles, los beneficiarios de la trata de negros, de las explotaciones del café, del tabaco, de azúcar. Martí que sabía todo esto tuvo pluma y palabras para descubrirlo, dice Espina, y dio una conferencia en el Ateneo de Madrid, en la que expuso con toda claridad y vehemencia el problema de Cuba y, no obstante su condición de deportado , también lo explicó en los pasillos del Congreso y en los claustros de la Universidad.

A comienzos de la primavera de 1873 , el estudiante universitario cubano solicita al Rector de la Universidad Central el traslado de su matrícula a la Universidad Literaria de Zaragoza. La Universidad de Zaragoza, (Navarrete, 1953:7) tuvo el privilegio de contar entre sus alumnos a dos jóvenes destinados a escalar las alturas de la fama. Uno de ellos, nuestro José Martí entre los libertadores de América, el otro Santiago Ramón y Cajal entre los sabios de Europa.

En aquella Universidad se graduó Martí en Derecho y en Filosofía y Letras. Martí se integró tan plenamente en la ciudad del Ebro y en la región de Aragón que tuvo unos versos de agradecimiento y recuerdo: Para Aragón en España, / Tengo yo en mi corazón / Un lugar; todo Aragón, / Franco, fiero, fiel, sin saña. // Si quiere un tonto saber / Por qué lo tengo, le digo / Que allí tuve un buen amigo, / Que allí quise a una mujer (Martí, 1995:173).

En Zaragoza termina su drama Adúltera, se gradúa de Bachiller (27 de junio), se licencia en Derecho Civil y Canónico (30 de junio) y en Filosofía y Letras (24 de octubre). El golpe de Estado del general Martínez Campos, (Espina, 1970:58) repercute en Zaragoza con trágicos, aunque rápidos, acontecimientos. Se produce resistencia en el pueblo, abundan los tiros y barricadas. El general Burgos, capitán general de la región, procede brutalmente contra todos cuantos ciudadanos no son avalados por párrocos o aristócratas; impone severas sanciones; cañonea barricadas y edificios, causando grandes estragos en San Ildefonso, la Calle Mayor y la Tripería; manda fusilar a cuantos vecinos son cogidos con armas e impone el orden después de tres días de combates callejeros.

No sabemos si Martí y su amigo Valdés permanecen escondidos durante esos breves días de resistencia del pueblo, pero desde luego son testigos, una vez más, de las barbaridades que se cometieron en la ciudad. Martí conoce perfectamente al pueblo aragonés y le convencen sus virtudes, como demuestra, sin duda, en- sus Versos sencillos: Y si un alcalde lo aprieta / 0 lo enoja un rey cazurro, / Calza la manta el baturro / Y muere con su escopeta (Martí, 1995:113) 
Antonio Espina menciona las palabras de un testigo presencial de los sucesos: "Los soldados tiraban a matar, no respetando mujeres ni niños". No cita la fuente, pero podían ser palabras de Martí. Dos meses después del golpe de Estado de Martínez Campos, Martí y su amigo Valdés Domínguez se salen de Zaragoza hacia Madrid y con documentación falsa cruzan la frontera francesa camino de Francia, donde en breve tiempo, absorbe toda la generosa experiencia del arte y la cultura que en ese instante puede brindarle Paris (Schultz, 1968: 17).

Su estancia en Paris es bien aprovechada, ya que a través del poeta Augusto Vacquerie, conocido en Madrid, le presenta a Víctor Hugo. Sin duda, durante esa breve, pero intensa estancia en la capital del Sena, contacta con los círculos literarios, visita museos y galerías de arte, la Universidad de la Sorbona y el Teatro de la Comedia. Durante esa estancia en París es cuando Víctor Hugo le confía la traducción al español de su obra Mes fils.

Sin embargo, su estancia en Francia tiene aún muchas zonas oscuras respecto a sus contactos no sólo literarios, sino también artísticos, culturales y sobre todo científicos. Respecto a sus raíces científicas francesas, escribe el periodista cubano (Schlachter, 1993:64) descubre en la revista Bohemia, que Martí regala a María Mantilla un libro, "L' Histoire Générale", muy corto, donde está muy bien contada y en lengua fácil y limpia toda la historia del mundo, desde los tiempos más viejos, hasta lo que piensan e inventan hoy los hombres.

El otro libro, continúa el escritor cubano, es para leer y enseñar: es un libro de 300 páginas ayudado de dibujos, en que está, María mía, lo mejor -y todo lo cierto- de lo que se sabe de la naturaleza ahora... Lee el último capítulo, La Physiologíe Végétale,la vida de las plantas, y verás qué historia tan poética y tan interesante. Yo la leo y la vuelvo a leer, y siempre me parece nueva... El escritor cubano llega a descubrir que se trata de dos libros del médico, fisiólogo y político francés Paul Bert (1833-1886), del que habla Martí en La Opinión Nacional de Caracas, el 26 de noviembre de 1881, a propósito de ciertos cambios ministeriales en Francia:

De la cartera de lo Interior se separa la de Cultos, que va a unirse por ley de analogía con la de Instrucción Pública, y ambas caen en las manos de un hombre que dice vehementemente lo que piensa maduramente, y reformará sin odio funesto lo que combate con brillante juicio: de Paul Bert, pensador muy osado y amigo del pensamiento libre y de hombres libres... La segunda obra de Bert a la que se refiere Martí es Curso de Enseñanza Científica.

De la admiración de Martí por el autor francés, Alexis Schlachter narra a continuación una anécdota que el mismo Martí cuenta en su Diario, el 2 de marzo de 1895, que durante su estancia en Haití se pierde y gracias a la ayuda de una familia campesina pudo proseguir el viaje: "Por dejarles una pequeñez en pago de su bondad les pido un poco de agua, que el muchacho me trae. $Y$ al ir a darle vinas monedas, Non, argent non; petit livre, oui (No, dinero no; el pequeño libro sí; en francés en el original). Por el bolsillo de mi saco asomaba un libro. El segundo prontuario científico de Paul Bert..." 
Y no sólo descubre esas raíces científicas martianas relacionadas con la ciencia francesa, pues el periodista cubano va más lejos y encuentra influencias alemanas en la cultura científica y filosófica de Martí: Yo he aprendido mi espiritualismo en los libros de Anatomía comparada y en los libros materialistas de Louis Buchner; y más adelante: Vogt escribe su admirable Anatomía comparada para deducir de ella la derivación innoble de nuestra especie de la no extinguida raza simia.

Señala, además, el estudioso cubano, que Martí sabía el alemán y para ello aporta varias citas de Martí, ya que sitúa en su parnaso como figuras indiscutibles a Calderón, Shakespeare, Esquilo y a los alemanes Schiller y Goethe: " $Y$ a aquella altura, nadie más", en palabras de Martí. A través de la Filosofía conoció también el mundo alemán, con gran influencia del krausismo; pero no sólo eso, sino que además invita Martí a los jóvenes estudiantes a "reunirse y estudiar asiduamente en privado a más del francés, el inglés y el alemán. Vive hoy fuera de su tiempo el no puede leer estas lenguas. Al hablar 'Martí de la Ilíada dice que "en inglés hay muy buenas traducciones, y el que sepa leer inglés debe leer 'La Ilíada' de Chapman o la de Landlor, que tienen más de Homero que la de Pope, que es la más elegante. El que sepa alemán, lea la de Wolf, que es como leer el griego mismo" (Schlachter, 1994:67).

Quizá estas investigaciones del periodista cubano Alexis, quien ya debe tener editado un libro sobre este tema, van a servir para un mejor entender al periodista científico, al crítico de arte y al periodista educador que descubriremos en las etapas posteriores de Martí. Por tanto, culturas que se suman a la conseguida en España y que nos servirán en gran medida para hallar muchas de las claves en la interpretación de la obra Martíana.

\subsection{Segunda etapa: México. Inicio de su periodismo total.}

Apenas llega Martí a México, donde se encuentra con su familia, inicia su periodismo que llamaremos total, ya que sin abandonar el periodismo político, el de ahora será mucho más amplio: científico, cultural, laboral, educativo, o simplemente informativo. Apenas llega a México inicia sus colaboraciones en la Revista Universal, de José Vicente Villada, el 7 de marzo, debido a la introducción de Manuel A. Mercado, quien sería su gran amigo. Su primera colaboración fue un poema dedicado a su hermana Mariana Matilde (Ana) fallecida el 5 de enero. El día 12 de marzo comienza a publicar como folletín en la Revista Universal de México (Quesada, 1947:91) su traducción de la obra de Víctor Hugo "Mes fils" ("Mis hijos"), encargo que había recibido en París del autor francés.

Participa en los debates sobre materialismo y espiritualismo organizados en el Liceo Hidalgo. Pronto pasa a ocupar en la Revista el cargo de boletinista: Ciencia es el conjunto de conocimientos humanos aplicables a un orden de objetos, íntima y particularmente relacionados entre sí, escribió Martí en un boletín titulado "Clases orales", con motivo de la inauguración de las clases orales en el Colegio de Abogados de México (Martí, 1875: Rev. Universal).

Su labor de periodista profesional en la Revista Universal comienza a destacar cuando inicia la redacción de los Boletines que firma con el pseudónimo de Orestes 
desde primeros de mayo de 1875 . En la misma revista entabla una polémica con La Colonia Española y La Iberia, periódicos de españoles residentes en México que atacaban a los insurrectos cubanos, incluso llegaron a mofarse de la bandera de Céspedes, llamándola "banderita": Banderita no; bandera. Dignísima palabra que cobija a un pueblo..., que tiene héroes activos y mártires errantes... (Schultz, 1968: 17).

En México, dice Henríquez Ureña (1977:14-15) se penetra cada vez más de las realidades que él llamó "Nuestra América". México, "significaría una de las escuelas donde más aprendió el modo de sentir americano" (Schultz, 1968,17).

Además, en la capital azteca descubre al indio al que hay que echar a andar (...) para que América pueda marchar adelante; hay que despertar de su espanto a la gran raza dormida (Henríquez, 1977:14). El periodista Martí político polemista comienza a dar paso al escritor de visión americanista total, continúa el autor antes mencionado. Pero habría que añadir aún más: Martí inicia todos los caminos de su periodismo total: Es el alma del periódico, dice el mexicano Juan de Dios Peza, compañero de redacción, el que escribe casi siempre el editorial, el Boletín, las Variedades, las Gacetillas, y si hubiera sido necesario, los anuncios, es aquel poeta y orador cubano, lleno de talento, de erudición, de elocuencia, que es una gloria de su patria y que se llama José Martí (García del Cueto, 1977:82).

Las palabras de su compañero de redacción nos descubre a un Martí, periodista pleno, que toca todos los géneros periodísticos y abarca toda la temática de aquel momento mexicano, dando pruebas de un periodismo "ágil, vibrante, reporteril, breve y lleno de colorido, que siempre acompaña de conceptos didácticos, impregnados muchas veces de un lenguaje sentencioso, como verdades irrefutables". Al referirse Rubén Darío (1905) al Martí periodista, a sus crónicas y boletines, dice: Allí aparecía Martí pensador, Martí filósofo, Martí pintor, Martí músico, Martí poeta siempre. Su visión total de periodista no quiere decir que abandone los temas cubanos, pues aparte de las polémicas, siempre que puede vuelve a insistir en el tema fundamental de su vida: la independencia de Cuba. Por ello, la misma Revista Universal, sale al paso de las críticas contra Martí y el 29 de mayo publica una "Solemne Declaración", en defensa del periodista y de la cuestión cubana.

Durante la presidencia de Lerdo de Tejada la situación en México comienza a ser delicada. Martí, aunque extranjero, tiene que pronunciarse sobre temas importantes. La crisis pone en peligro la estabilidad del régimen de Lerdo, y el escritor cubano, desde las páginas de la Revista Universal, entra en el debate sobre problemas económicos y se declara partidario del liberalismo defendido por Guillermo Prieto e Ignacio Ramírez. Por su artículo "Protección y Libre Cambio" del día 9 de octubre, fue duramente criticado por el poderoso periódico conservador El Monitor Republicano.

Con motivo de la guerra civil y del triunfo de Porfirio Díaz la Revista Universal tuvo que cerrar. El 19 de noviembre de 1876 Martí escribe en ella por última vez. Unos días más tarde Porfirio Díaz hace su entrada triunfal en la capital. José Martí aún permanece un poco tiempo en la capital y hasta se atreve a escribir en El Federal un artículo titulado 
"La Situación" en el que se declara en contra del dictador Porfirio Díaz. En diciembre de ese mismo año sale de México hacia Guatemala.

A principios de 1877 llega Martí a Guatemala, país en el que sus actividades iban a ser fundamentalmente docentes, primero en la Escuela Normal y después en la Universidad, donde conquista muchos adeptos despertando entusiasmo entre la juventud. Su fama de orador también se extiende rápidamente. Escribe en la revista de la Universidad temas referentes a la docencia. Pero, de nuevo trata de ejercer el periodismo, ya que concibe la idea y hasta llega a escribir el prospecto de una publicación periódica que debía llamarse Revista Guatemalteca, que deberla aparecer en abril de 1878. De nuevo vuelve a aliarse con la verdad en defensa de la justicia, lo que le lleva a la renuncia de sus cargos como profesor ante el presidente, en solidaridad con un compatriota, Izaguirre, quien se había visto forzado a presentar su renuncia como director de la Escuela Normal.

Al término de la Guerra de los Diez Años se produce la Paz del Zanjón por lo que Martí vuelve a Cuba por un breve tiempo durante el que desarrolla una intensa actividad cultural sobre todo a través de sus intervenciones como orador en el Liceo de Guanabacoa. Aunque no ejerce el periodismo, Martí es acusado de nuevo de conspirar contra el Gobierno y es deportado a la Península por orden del General Blanco. En setiembre, día 17 es detenido y el 25 parte hacia su destierro. Desembarca en Santander el 11 de octubre, en cuya cárcel permanece un par de días, ya que fue rescatado por el aval de un diputado de Laredo, que al parecer coincide con él en viaje hacia España. En la ciudad cántabra visita a su madrina y después se dirige a Madrid y se entrevista con Cristino Martos el día 19 de noviembre. Antes de terminar el año embarca para Nueva York, donde llega el día 3 de enero de 1880. Algunos historiadores señalan que Martí vuelve a visitar algunas ciudades españolas antes de marcharse, lo que parece bastante razonable. Lo inverosímil es que pudiera visitar en pocos días varias ciudades europeas, según aseguran otros biógrafos, a no ser que lo hiciera antes de pasar por Madrid para entrevistarse con Cristino Martos. Lo que sí es cierto es que desde Madrid se encamina a París, donde conoce a Sarah Barnhardt, embarcándose después para los Estados Unidos.

\subsection{Tercera etapa: El gran periodismo.}

En la etapa estadounidense Martí desarrollará su más intensa labor periodística a escala continental. A poco de llegar a Nueva York, 3 de enero de 1880, el pintor cubano Guillermo Collazo le relaciona con la revista de arte The Hour (La Hora), en la que Martí comienza sus colaboraciones como crítico de arte.

El día 21 de febrero de 1880 aparece en The Hour su primer artículo en inglés "Raimundo Madrazo". Para la revista The Hour escribe en inglés, aunque muchos de los borradores de sus crónicas estaban redactados en francés, hecho comprensible ya que él mismo anota en sus papeles al iniciar su nuevo trabajo: "Yo sé un inglés bárbaro, y estas cosas me parecían justas, y me oprimían el corazón. Pero yo tengo confianza en mi energía y en estos ardientes afectos que involuntariamente inspiro... Escribí, temblando, mi revista artística. Yo sabía que escribía español con palabras 
inglesas..." (Martí, 1882)

Martí consigue tal éxito con sus crónicas de arte, a pesar de su "inglés bárbaro" que el público llega a comprar la revista The Hour atraído por las magníficas crónicas de Martí: "El hecho es que agradan a los lectores y sus juicios, finos y originales, constituyen una atracción en las páginas de la revista". A través de esta revista, Martí conoce a Charles Anderson Dana, director del periódico The Sun (El Sol), estableciéndose una amistad entre ambos. Dana solicita las colaboraciones de Martí para su periódico de gran tirada. En el periódico de Dana el periodista cubano, además de sus impresiones sobre América en general, va a escribir crónicas sobre la vida norteamericana, que 'consiguen un gran éxito, ya que Martí escribe lo que le parece justo. Cuando Dana leía sus críticas de arte en The Hour sabía que no se equivocaría si solicitaba sus crónicas para su periódico. Su primera colaboración para el Sun versa sobre Bouard y Pécuchet de Flaubert, el 8 de julio de 1880. Recogemosunos párrafos de una crónica "New York y el arte" sobre una exposición de los impresionistas en Nueva York: "acá están todos, naturalistas e impresionistas, padres hijos; Manet con sus crudezas, Renoir con sus japonismos, Pisarro con sus brumas, Monet con sus desbordamientos, Degas con sus tristezas y sus sombras".

"Ninguno de ellos ha vencido todavia. La luz los vence, que es gran vencedora. Ellos la asen por las alas impalpables, la arrinconan brutalmente, la aprietan entre sus brazos, le piden sus favores; pero la enorme coqueta se escapa de sus asaltos y sus ruegos, y sólo quedan de la magnífica batalla sobre los lienzos de los impresionistas esos regueros de color ardiente que parecen la sangre viva que echa por sus heridas la luz rota: iYa es digno del cielo el que intenta escalarlo!"

Las palabras de Martí se refieren a la segunda exposición de los impresionistas en Nueva York. Martí escribe diversas crónicas sobre el impresionismo, crónicas que llegan a causar admiración y que contrastan vivamente con las realizadas por los periodistas norteamericanos del momento que no comprenden el impresionismo. Eduardo Degas en sus "Memorias" cuenta la sorpresa que le causaron los artículos y el profundo conocimiento de un periodista y escritor antillano, que había hecho críticas muy certeras de los impresionistas, mientras el resto de los críticos no entendía nada y hasta habían combatido la exposición.

En contra de los consejos de los amigos venezolanos y del propio Dana, Martí decide ir a Venezuela. El propio Dana le ayuda a cambio de que le enviara crónicas para su periódico. En enero de 1881 llega Martí a Caracas y lo primero que hace nada más llegar es ir a visitar la estatua de Bolívar. Para sobrevivir, comienza a dar clases de gramática francesa y de literatura en los Colegios Santa Maria y Guillermo Tell Villegas; en este último establece una escuela de oratoria. En el mes de junio de 1881 comienza a colaborar en La Opinión Nacional, de Caracas y el día 1 de julio Martí publica la Revista Venezolana. En el segundo y último número, de 15 del mismo mes, publica un artículo elogioso sobre Cecilio Acosta, prócer colombiano que había fallecido. Como Cecilio Acosta había sido opositor a la dictadura de Guzmán Blanco, el articulo de Martí no gusta al presidente, hecho que determina, tras una borrascosa entrevista con el dictador, que el escritor cubano tuviera que abandonar Venezuela y 
regresar de nuevo a Estados Unidos.

Desde Nueva York comienza a enviar sus crónicas a La Opinión Nacional con el seudónimo M. de Z., hasta diciembre en que deja de escribir en el periódico de los Aldrey, ya que Martí había recibido una carta en la que se le daban ciertas directrices sobre algunos temas, especialmente sobre los referentes a los que tratasen sobre los Estados Unidos- Martí responde con el silencio más absoluto. Durante ese tiempo también escribe para La Pluma de Bogotá. En 1882, publica Ismaelillo, dedicado a su hijo. Al mismo tiempo escribe gran parte de sus Versos Libres. Precisamente en julio de ese mismo año comienza a redactar las "correspondencias" para La Nación de Buenos Aires. La primera en aparecer, el 13 de setiembre, fue "Muerte de Guiteau". El escritor cubano publica en La Nación de Buenos Aires más de doscientas crónicas. Los Mitre también escriben a Martí que sus artículos eran brillantísimos, pero demasiado negativos. La respuesta de Martí fue que, aparte de dar lo positivo, también daría lo negativo, "pues nuestros pueblos tienen que conocer la realidad". Hay en Martí, dice Portuondo, el mejor crítico de la vida americana y sus Escenas norteamericana constituyen un brillantísimo panorama de lo que eran los Estados Unidos.

Llega a ser director de la revista La América en 1884. Muchos de sus trabajos en esta revista son importantes colaboraciones sobre temas de enseñanza. La enseñanza en el campo, los maestros ambulantes, las reformas educacionales en los Estados Unidos, etc. En 1885, publica en varias entregas en el periódico El Latino Americano la novela Amistad funesta, con el seudónimo de "Adelaida Ral". Colabora, además, en El avisador cubano, de Nueva York. Al año siguiente, el 15 de mayo, escribe su primera correspondencia para El Partido Liberal de México y el 8 de julio inicia también su primera correspondencia para La República de Honduras; y, por otra parte, colabora en el Economista Americano, de Nueva York, en el que escribe extraordinarios planteamientos sobre problemas económicos. También colabora en El Avisador Hispanoamericano, El Porvenir, La Revista Ilustrada y en La Juventud, este último de Gonzalo de Quesada. Durante el año 1887, "más de 20 periódicos de América Latina reproducen sus artículos de La Nación, de Buenos Aires, y El Partido Liberal, de México"

En marzo de 1889, publica en The Evening Post "Vindicación de Cuba", en respuesta a la reproducción que el diario hizo de un articulo "Cuba y los Estados Unidos", del periódico de Filadelfia, The Manufacturer, que trataba de la compra y anexión de Cuba por los Estados Unidos y en el que se menospreciaba a los cubanos. Este año de 1889, por otra causa, iba a representar una de sus más altas cotas periodísticas. Aparecerá La Edad de Oro revista para niños. Fue una forma de periodismo para niños, no sólo desusada en aquella época, sino que además fue la primera manifestación de periodismo de este tipo, al menos dentro del mundo hispánico. La Edad de Oro Publicación mensual de recreo e instrucción dedicada a los niños de América, (julio de 1889), conquistó a los niños de América desde su salida, ya que en la revista iban a encontrar información sobre muchas cosas.

Martí pretendía una educación total para los niños a través del periodismo. Desde la historia, la geografía, el arte, la técnica, las ciencias, la cultura, la literatura, hasta la 
misma cosmología: "les vamos a decir cómo está hecho el mundo...". Las ambiciones de Martí respecto a la infancia de América eran infinitas: Aparte de la actualidad que Martí lleva a las páginas de su revista y la actualidad que infunde a todos sus escritos nos refleja su fidelidad a que "la prensa no debe sólo informar, sino también formar". La prensa informadora y al tiempo formadora es la razón de ser de La Edad de Oro. La revista, que iba a ser mensual, sólo apareció cuatro veces, durante los meses de julio, agosto, septiembre y octubre de 1889. "Sólo cuatro números llegan a publicarse: ellos forman una obra literaria de valor único, escrita como desde una mentalidad infantil, con toda su fresca belleza; una obra que, en su género, nadie ha logrado igualar en español, ni acaso en ningún idioma" ya que Martí sufre una decepción por parte del editor, A. Dacosta Gómez, quien critica a Martí porque su revista nunca hablaba de Dios a los niños y que no daba una orientación religiosa a los niños católicos de habla hispana. Como en alguna otra ocasión, Martí obra de forma independiente, no se deja manipular, ya que él tiene una concepción más amplia, pues se dirige a todos los niños de América sin distinción de raza, color, religión... Quebró la empresa, porque Martí no aceptó transformar su revista de modo que difundiera esas ideas, y cesó la publicación. Así murió la única revista para niños que se había hecho hasta entonces en nuestra lengua.

\section{5 Última etapa: La Revolución y Patria (1889-1895).}

Sin embargo, el periodismo de Martí llega a su cumbre con el periódico del Partido Revolucionario Cubano, Patria, (14 de marzo de 1892). Este periódico iba a ser su obra maestra, ya que en él va a verter el autor todo lo que entiende que debe ser la prensa ideológica del movimiento libertador. No obstante, en esta su obra maestra, tampoco olvida Martí que el periodismo además de informar debe formar. Por ello, se reafirma, como siempre, su postura respecto a que el periódico debe ser fundamentalmente formador $\mathrm{y}$, desde el primer número manifiesta lo que debe ser el periodismo de Patria:

"El periódico ha de estar siempre cono los correos antiguos, con el caballo enjaezado, la fusta en la mano y la espuela en el tacón. Al menor accidente, debe saltar sobre la silla, -sacudir la fusta y echar a escape el caballo para salir pronto y para que nadie llegue antes que él. Debe, extractando libros, facilitar su lectura a los pobres de tiempo, -o de voluntad o de dinero."

El día 2 de mayo de 1895, a pocos días de su muerte, redacta una carta manifiesto al director del New York Herald, sobre los motivos y principios de la guerra, entregándosela al corresponsal G. E. Bryson. El 14 de mayo, en unión del general Gómez, firma la Proclama a los jefes y oficiales del Ejército Libertador. El día antes de su muerte, día 18, escribe una carta a su amigo Manuel A. Mercado, que deja sin concluir: "Sobre la tabla de pino que en el campamento le había servido de mesa quedó inconclusa su última carta a Mercado. Y queda su último trabajo de periodista: un artículo escrito para el Herald de Nueva York, el 2 de mayo de 1895, en el que definía el destino de Cuba: Cuba quiere ser libre para que el hombre realice en ella su ser pleno. 
El día 19 de mayo de 1895, después de arengar a las tropas, cae mortalmente herido en la acción de Dos Ríos, el hijo más preclaro de Cuba, el "Apóstol de nuestras libertades", "el mejor hombre de nuestra raza". Quien murió allá en Cuba, era de lo mejor, de lo poco que tenemos nosotros los pobres; era millonario y dadivoso: vaciaba su riqueza a cada instante, y como por la magia del cuento, siempre quedaba rico: hay entre los enormes volúmenes de La Nación, tanto de su metal fino y piedras preciosas, que podría sacarse de allí la mejor y más rica estatua. $Y$, sin duda, fue el mejor periodista del siglo XIX, precursor del modernismo y del nuevo estilo periodístico: Hay tanto que decir, se había expresado en una ocasión, que ha de decirse con el menor número de palabras: eso si, que cada palabra lleve alas y color. Por ello, Rubén Darío le reprocha cariñosamente al recordar su muerte: Perdona que te guardemos rencor los que te amábamos y admirábamos, por haber ido a exponer y a perder el tesoro de tu talento.

Un trabajo tan corto como éste resultaría demasiado pretencioso, si juzgara haber profundizado en la obra periodística del héroe cubano, pero ni siquiera haber conseguido un esbozo aproximado de su vasto mundo de la comunicación, ya que según Gabriela Mistral tiene aún muchos filones por explotar. Por ello, concluye este recuerdo-homenaje de las Monográficas dedicadas a José Martí en las I Jornadas de Periodismo Iberoamericanos celebradas en la Facultad de Ciencias de la Información, que han tratado sobre Martí comunicador, para despertar el interés por su gran figura, probando que fue el máximo periodista del siglo XIX y uno de los precedentes más significativos y de mayor influencia a tener en cuenta ante las efemérides recapituladoras del próximo 98.

\section{BIBLIOGRAFÍA}

Darío, R. (1905): José Martí en Los raros. Barcelona. Maucci.

Espina, A. (1970): Martí. Madrid. Compañía Bibliográfica Española.

García, M. (1977): "Martí, periodista". En El periodismo de José Martí. La Habana. Orbe.

García, J. A. (1977): "El compañero José Martí". En El periodismo en José Martí. La Habana. Orbe.

Henríquez, C. (1977): "En torno a Martí, el periodista". En El periodismo en José Martí. La Habana, Orbe.

Lizaso, F. (1943): Trabajos periodísticos de José Martí. La Habana.

Marinello, J. (1977): Cronología, La. 
Martí, J. (1939-1959): O. C. La Habana

(1955): Versos sencillos. Madrid. Alianza Editorial.

(1873): La República española ante la Revolución cubana. Madrid.

(1871): El estado de las cárceles en Cuba. Madrid.

(1889): La Edad de Oro. Nueva York.

(1892): Patria. Nueva York.

(1886): "Nueva York y el arte" en La Nación, Buenos Aires.

Navarrete, A. (1953): Martí, estudiante universitario. La Habana.

Quesada, G. (1947): Guía para las obras completas de Martí. La Habana. Trópico.

(1977): Así fue Martí. La Habana. Gente Nueva.

Ripoll, C. (1971): Archivo José Martí. Repertorio crítico. Nueva york.

Schlachter, A. (1993): "El último libro que regaló Martí" en Bohemia, 14 de mayo. La Habana.

(1994): "Lo alemán en la cultura universal de Martí" en Bohemia, 16 de septiembre, La Habana.

Schultz, F. (1968): Genio y figura de José Martí. Buenos Aires. De. Universitaria.

\section{Enrique Ríos Vicente}

Profesor del Departamento de Historia de la Comunicación Social en la Facultad de Ciencias de la Información. Universidad Complutense de Madrid (España) y Presidente de la Sociedad Española de Estudios de la Comunicación Iberoamericana (SEECI) (España). Director de varios másteres y títulos propios y articulista especializado en temas de Hispanoamérica. 